\title{
Development and Improvement of Educational Exchanges between Belarus and China
}

\author{
Kseniya KARNATSEVICH ${ }^{1}$, Wei-Hua FANG ${ }^{2}$, Abdulla Mousa Falah ALALI ${ }^{3}$ \\ ${ }^{1}$ Beihang University, School of Humanities and Social Sciences, \\ Postgraduate School, Beijing, PRC \\ ${ }^{2}$ Beihang University, School of Humanities and Social Sciences, Beijing, PRC \\ ${ }^{3}$ Beihang University, School of Humanities and Social Sciences, \\ Postgraduate School, Beijing, PRC \\ wstorkk@qq.com, booklook@china.com, alali_abdalla@hotmail.com
}

Keywords: Academic mobility, Belarus-China educational exchanges, Educational cooperation, Belarus-China platform of specialties, Triple helix, Innovations, Economy development.

\begin{abstract}
Today the dynamic of Belarus-China educational exchanges rapidly increasing. With the spreading globalization increased the integration of the universities into the international educational space. One of the main roles in such cooperation plays a mobility of students and teachers. Educational exchanges contribute to the formation of a qualitatively new workforce, able to take its rightful place in the national economy and the global labor market. In this work, will be considering the weaknesses of current and prospects for future development of Belarus-China educational exchanges. Also there are will be presented a Belarus-China platform of specialties. That platform was created on the base theory of the triple helix model where all three structures government, university and business integrate with each other and create innovations. Such platform of specialties will contribute to the development and improvement of educational exchanges and regions of China and Belarus.
\end{abstract}

\section{Introduction}

Since the beginning of the 60s of the 20th century, cultural and educational exchanges between the Belarus and China have been increased. Since the 1990es the cooperation between the Republic of Belarus and the People's Republic of China is slowly but steadily growing.

The cooperation between the states in the field of education and culture leads to strengthen their cooperation in other spheres, particularly in economy and politic. With spreading globalization the academic mobility became one of the main indicators of the development of educational standards in the country.

Educational exchanges between the Republic of Belarus and the People's Republic of China by the time have passed different stages of improvement and development, but till now has some weaknesses which effect current educational cooperation . During the research have been found some main limiting factors, such as using the outdated education system and management in the educational institutions, which cannot ensure the high efficiency for today and cannot prevent a quick respond and implementation of the updated educational. All this redacts the effectiveness of the educational programs in international educational market. Therefore it is bad effect for the development of educational cooperation between Belarus and China.

Thus the task was to propose the solution for solving existing weaknesses in educational exchanges between the Belarus and China, and which will develop and improve the educational exchanges between the countries in a future. 


\section{Method: Triple Helix Model}

Globalization dictates its new directions and the trends for cooperation development between the Belarus and China in political, economic, humanitarian, educational and cultural relations.

One of these world trends currently is an American triple helix model theory. The triple helix theory based on the close interaction between the state, enterprise and institution and suggests the origin usages of knowledge of the economy and innovations. [1]

The theory of the "Triple Helix" defines the increasingly important role of the university in relation to business and government. In its modern mission of the university associated with the obtaining of new knowledge and innovation, aimed at developing the economy and the state as a whole. [2]

The leaders in the international arena become countries, which develop and identify of new technologies. Belarus and China in educational cooperation are also follows these trend. By the recently years between the Belarus and China have been increased the educational cooperation particularly in science and innovations.

In the course of our development the universities are beginning to play an increasingly important role.[3] Universities are the most flexible of all the institutions known to us in terms of the generation and dissemination of knowledge. [4] Speaking as an equal partner with the institutional business and the state, universities are one of the elements in the triple helix model and occupy the leading position in a society based on knowledge.

All three institutional spheres, universities, business and government have their traditional mission, but begin to play a new role, serving as the other institutional spheres. [5]

\section{Implementation of Triple Helix Theory into the Belarus-China Platform of Specialties}

After analyzing the Belarus-China educational exchange programs, I came to the conclusion that it is important to make some improvements in the development of educational exchanges between the Belarus and China. During the study of this issue have been revealed that the Belarus-China educational exchanges do not meet the current needs of these states and enterprises. For example, in Belarus there are shortages of qualified personnel for the common China-Belarus projects. There are some personnel that partially meet the needs of the modern market, but to find personnel fully meet the required criteria and requirements is difficult.

For my opinion to solve the shortages of qualified personnel could be a creation of a ChinaBelarus platform of specialists. This China-Belarus platform of specialists involves new parallels of cooperation between universities, businesses and states. This platform will include two states, educational institutions and research centers, enterprises and companies.

The implementation of this model will solve some Belarus-China educational exchanges problems, such as preparation of necessary specialists for the enterprises, increased time for practice in enterprises, collaboration of governments, enterprises and universities in a special way, employment of the participant of the program, high returns to the state and to the enterprises, creation of innovations and economy development.

\section{Structure of the Belarus-China Platform of Specialties}

Created the Belarusian-Chinese platform of specialties will involve close interaction between governments, universities and enterprises. This platform of specialties can be offered as one of the solutions for improving existing weaknesses of Belarus-China educational exchanges.

On the scheme 1 shows the structure of the relationship of the main elements. This structure consists of a base of required specialties and qualification criteria, employers and educational institutions. There are we can find the data about the skill requirements, consumers of the staff and educational institutions. 
Scheme 1. Belarus-China Platform of Specialties

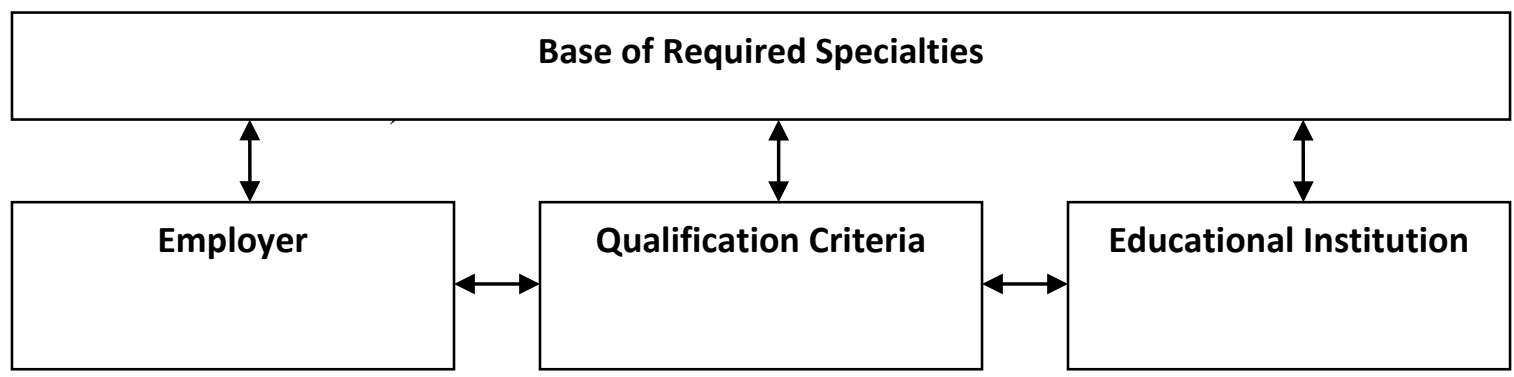

A base of required specialties will include the list of all required now and in future different specialties in China and Belarus. The list should be sorted by industry.

Employer - are those who require the specialized experts from the base of required specialties. Employer can be various public entities and municipalities, private companies and individuals, hospitals and shops, etc.

Qualification criteria - are those requirements that must be met by a specialist in the enterprise. Now different companies require staff with different qualification requirements. It may be a certain skills, different levels of qualification, knowledge of languages, required experience, healthcare, etc.

Educational institution - are those institutions that teach or re-educate staff of various professions. These are can be a public and private universities, commercial organizations and online learning structures and so on.

That is, the Belarus-China platform of specialties can be considered as an option for the improvement of organization of educational exchanges. Such platform of specialties can help to combine the efforts of both states and to obtain economic benefits from possession of information about skill requirements and the ability to prepare specialists and to employ. That is, the BelarusChina platform of specialties represents a general database of specialties from which a juridical person or individual can select a qualified professional.

In addition, through this platform will strengthen the relationships between all the key elements (states, universities, enterprises), which in turn will help to better educate and prepare necessary specialists for the Belarus-China projects.

The most important resource of the states become professionals. Improving the quality of training of specialists will help Belarus and China to possess a competitive advantage in the global market.

Unfortunately, today's training of professionals, involved in Belarus-China educational exchanges are not fully meet the requirements of today's educational market, which is fast enough is updated and where today there is still no synchronization between the different institutional elements of the two States.

Creation of the Belarus-China base of specialties would help to solve not only existing problems such as lack of staff with special eligibility requirements and a glut of the market with specialists of some industries, while helping to improve and refine the interaction between the states, universities and businesses and would contribute to ongoing monitoring, development and modernization of educational programs.

\section{Discussions and Conclusion}

Throughout the development of Belarus-China educational cooperation were and are some problems which prevent more rapid development in this field. Despite long accumulated experience of educational exchanges between the Republic of Belarus and the People's Republic of China, there are still not enough specialists for common projects, experts after the exchange programs work in other professional fields and enterprises do not develop at the expense of necessary personnel. 
The creation of the Belarus-China platform of specialties could minimize existed shortage of specialists and be a directional platform for the development and modernization of the educational exchanges. The integration of all three components in this platform: universities, enterprises and the states also could solve the problem of more productive China-Belarus cooperation in the sphere of education. Implementation of China-Belarus platform of specialties could give a new impetus to the relationship of the countries in the sphere of education.

\section{References}

[1] H.Etzkowitz, Triple helix: Universities - Enterprises - State , TUSUR, Tomsk, 2010.

[2] V. A.Sergeev, The innovative mission of the University, Innovations, № 1-2, 2010.

[3] N. P.Kirillov, Y. S. Plotnikov, Magic method, Tomsk State University, Tomsk, 2013.

[4] N. P. Kirillov, Y. S. Plotnikov, Magic method, 2-nd edition. extra , TPU, Tomsk, 2014.

[5] I.G.Dezhin, V.V.Kiselev, State, Science and Business in the Innovation System of Russia, Institute of Economy in transition, 2012. 